\title{
APERFEIÇOAMENTO DAS PROPRIEDADES CATALÍTICAS DE LECITASE IMOBILIZADA UTILIZANDO POLÍMEROS IÔNICOS
}

\author{
J.C.S. DOS SANTOS ${ }^{1,2}$, C.GARCIA-GALÁN ${ }^{1}$, R. C. RODRIGUES ${ }^{3}$, H. B. SANT'ANA ${ }^{2}$, L. R. B. \\ GONÇALVES ${ }^{2}$, ROBERTO FERNÁNDEZ-LAFUENTE ${ }^{1}$ \\ ${ }^{1}$ Universidad Autónoma de Madrid. Instituto de Catálisis y Petroleoquímica-CSIC. \\ ${ }^{2}$ Universidade Federal do Ceará, Departamento de Engenharia Química. \\ ${ }^{3}$ Universidade Federal do Rio Grande do Sul, Instituto de Ciência e Tecnologia dos Alimentos. \\ E-mail para contato: jscleiton@gmail.com
}

\begin{abstract}
RESUMO - Lecitase Ultra foi imobilizada em brometo de cianogênio-agarose (através de ligação covalente) e em octil-agarose (através de ativação interfacial). As preparações imobilizadas foram incubadas em soluções de dextrano sulfato (DS) ou polietilenimina (PEI), para o revestimento de superfície da enzima. Em seguida, a atividade sob diferentes condições experimentais foi avaliada. A incubação com DS produziu uma diminuição significativa da atividade, usando CNBr-Lecitase, cerca de 50\% e usando octil-Lecitase, foi de apenas cerca de $30 \%$. A incubação com PEI produzido um efeito completamente diferente, usando octil-Lecitase a atividade aumentou em 30\% enquanto com $\mathrm{CNBr}$ Lecitase aumento mais duas vezes. Assim, os efeitos do revestimento com polímeros iônicos depende fortemente das condições experimentais e da técnica de imobilização utilizada.
\end{abstract}

\section{INTRODUÇÃO}

Lecitase Ultra é uma fosfolipase A1 quimera artificial, desenvolvida principalmente para processos de degomagem, embora fosfolipases A1 tenham usos diferentes na indústria. Esta enzima tem sido obtida a partir da fusão dos genes do lipase de Thermomyces lanuginosus (para obter uma boa estabilidade) e a fosfolipase de Fusarium oxysporum (para obter uma atividade de fosfolipase). Em alguns aspectos, Lecitase Ultra comporta-se como uma enzima lipase padrão, com a capacidade de se tornarem adsorvidas em superfícies hidrofóbicas em baixa força iônica (por exemplo, suportes hidrófobos) e apresentando uma ampla especificidade, segundo De Maria et al. (2007) e FernandezLorente et al. (2007).

As propriedades das lipases (seletividade, especificidade) podem ser modulados. A modificação química é uma ferramenta poderosa para modular as propriedades das lipases, como alguns relatos na literatura mostrando o potencial dessa estratégia, como mostra Barbosa et al. (2012); Garcia-Galan et al. (2014) e Santos et al. (2014).

Assim, neste trabalho, mostramos as mudanças na atividade de Lecitase Ultra, especificidade e estabilidade, após o revestimento com dois polímeros diferentes, dextrano sulfato (DS) ou polietilenimina (PEI). A fim de verificar o efeito do protocolo de imobilização na modulação das 


\section{9 a 22 de outubro de 2014 \\ Florianópolis/SC}

propriedades da enzima através de revestimento com polímero, foi utilizado uma estratégia de imobilização onde a forma aberta da enzima é estabilizada (utilizando imobilização reversível através da ativação interfacial em octil agarose) e uma outra em que ligação covalente é efetuada (usando brometo de cianogénio de agarose sob condições suaves para reduzir o número de ligações de enzima /suporte) como descrito nos trabalhos de Fernandez-Lafuente et al. (1998) e Santos et al. (2014).

\section{MATERIAIS E MÉTODOS}

Lecitase foi da Novozymes (Espanha). Octil-agarose e brometo de cianogênio reticulado 4\% agarose (CNBr) eram da GE Healthcare. Polietilenimina (Mn 10000, Mw 25000), sulfato de dextrano (9000, 20000 Av. wt), p-nitrofenil butirato (p-NPB), R e S-metil mandelato, hexanoato de etilo, éter de p-nitrofenilfosfato (D-pNPP) e fenilacetato de metilo foram da Sigma Chemical Co. (St. Louis, MO, EUA). Glutaraldeído ( $25 \%$, v/v estabilizado em etanol) foi da Fluka. Todos os reagentes e solventes eram de grau analítico.

\subsection{Determinação da atividade da enzima}

Este ensaio foi realizado através da medição do aumento da absorbância a $348 \mathrm{~nm}$ produzidos pela liberação de p-nitrofenol na hidrólise de $0,4 \mathrm{mM}$ de p-nitrophenylbutyrate (p-NPB) em fosfato de sódio $100 \mathrm{mM}$ a pH 7,0 e $25{ }^{\circ} \mathrm{C}$ (sob estas $\varepsilon$ condições é $5150 \mathrm{M}^{-1} . \mathrm{cm}^{-1}$ ). Uma unidade internacional de atividade (U) foi definida como a quantidade de enzima que hidrolisa $1 \mu$ mol de p-NPB por minuto sob as condições descritas anteriormente. A concentração de proteína foi determinada utilizando o método de Bradford (1976) e de albumina de soro bovino foi utilizada como referência.

$\mathrm{Na}$ determinação dos efeitos do valor do $\mathrm{pH}$ sobre a atividade da enzima, o protocolo seguido foi semelhante, mas o tampão nas medições foi alterado de acordo com o valor de $\mathrm{pH}$ : de acetato de sódio a pH 5, fosfato de sódio a pH 6-8 e borato de sódio a pH 9 e pH 10.

\subsection{Imobilização de Lecitase em octil-agarose}

Lecitase foi imobilizada em octil-agarose em baixa força iônica, de acordo com FernándezLorente et al. (2007). 2,8 mL de extrato comercial (16 mg de proteína / mL, com uma atividade pNPB de 5,6 U / mg de proteína) foi diluída em 67,5 mL de fosfato de sódio $5 \mathrm{mM}$ a pH 7. Em seguida, foi adicionado $15 \mathrm{~g}$ de octil-agarose. Atividade de sobrenadante e suspensão foi seguida usando pNPB. Depois, a suspensão foi filtrada e a lipase imobilizada foi lavada várias vezes com água destilada.

\subsection{Imobilização de Lecitase em CNBr -agarose}

Um volume de 2,8 $\mathrm{ml}$ de Lecitase comercial foi diluída em $67,5 \mathrm{~mL}$ de fosfato de sódio $5 \mathrm{mM}$ contendo $0,05 \%(\mathrm{~m} / \mathrm{v})$ de dodecil sulfato de sódio a $\mathrm{pH} 7$, e $4{ }^{\circ} \mathrm{C}$. Em seguida, foi adicionado $15 \mathrm{~g}$ de $\mathrm{CNBr}$. Atividade de sobrenadante e suspensão foi seguida usando pNPB. A imobilização da enzima foi terminada por incubação do suporte com etanonamina 1M, a pH 8, durante $12 \mathrm{~h}$. Finalmente, a preparação imobilizada foi lavada com água destilada abundante. 


\subsection{Revestimento de Lecitase imobilizada com polímero iônico}

Uma massa de $10 \mathrm{~g}$ de Lecitase imobilizada foi adicionada a $100 \mathrm{~mL}$ de PEI a pH 7 ou a pH 5 de soluções DS a concentração do polímero desejado. Atividade durante a incubação foi seguida pela atividade de pNPB, como no protocolo descrito acima.

\subsection{Inativação térmica de diferentes preparações de Lecitase imobilizada}

Para verificar a estabilidade dos derivados, $1 \mathrm{~g}$ de enzima imobilizada foi suspenso em $5 \mathrm{~mL}$ de $10 \mathrm{mM}$ de acetato de sódio a pH 5, fosfato de sódio a pH 7 ou carbonato de sódio, a pH 9, a diferentes temperaturas. Periodicamente, foram retiradas amostras e a atividade foi medida utilizando-se pNPB. As meias-vidas foram calculadas a partir dos cursos de inativação observados.

\subsection{Inativação de diferentes preparações de Lecitase em presença de co-solvente orgânico}

Preparações de enzima foram incubados em mistura de acetonitrilo a 30\% em $100 \mathrm{mM}$ de Tris$\mathrm{HCl}$ a 7 e $25^{\circ} \mathrm{C}$ para prosseguir com a desativação. Periodicamente, foram retiradas amostras e a atividade foi medida utilizando-se pNPB. As meias-vidas foram calculadas a partir dos cursos de inativação observados.

\section{RESULTADOS}

\subsection{Efeito do revestimento com DS e PEI na atividade da Lecitase Ultra}

Em primeiro lugar, os efeitos na atividade enzimática dos dois polímeros iônicos solúveis foram analisados. Enzima livre e PEI foram misturados, e um incremento inicial de atividade da enzima (após 2 horas da atividade chegou a 200\%) foi encontrado, mas mais tarde a atividade da enzima diminuíram até valores próximos aos iniciais. Usando DS e enzima livre, a atividade permaneceu inalterada após $24 \mathrm{~h}$. Apesar de não apreciar aumento da solução (usamos 0,05 mg de proteína/ $\mathrm{ml}$ ), a possibilidade de algum tipo de agregação que poderia mascarar os efeitos do revestimento de polímero não podem ser descartadas. Então, decidimos focar no uso da enzima imobilizada, onde a formação de agregados não é possível.

A Figura 1 mostra o efeito sobre a atividade da enzima durante incubação de $\mathrm{CNBr}$ e octilLecitase em recipiente contendo soluções de PEI ou DS, com $50 \mathrm{mg}$ de polímero por g de suporte. Incubação com DS produziu uma significativa diminuição na atividade. Usando CNBr Lecitase, após uma primeira queda rápida de cerca de 50\%, a atividade foi estabilizada após $24 \mathrm{~h}$ de incubação. Usando octil-Lecitase, a diminuição da atividade foi de apenas cerca de $30 \%$. 


\section{9 a 22 de outubro de 2014 \\ Florianópolis/SC}
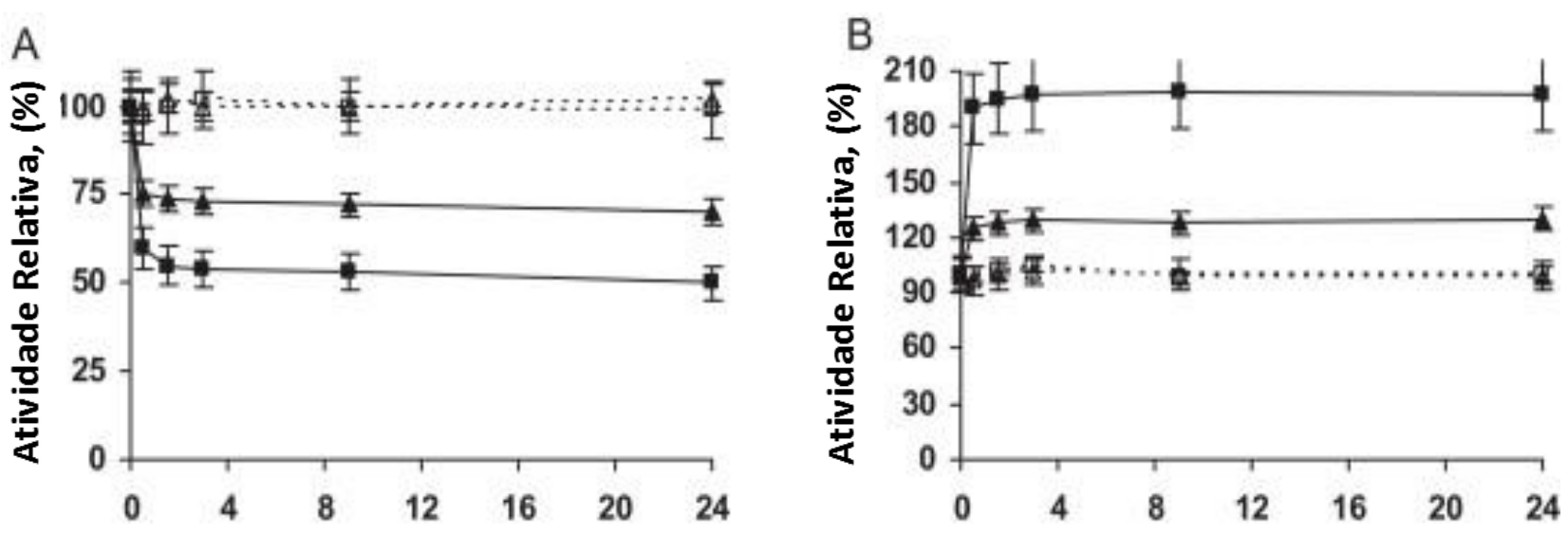

Tempo, (horas)

Tempo, (horas)

Figura 1 - Efeito soore a atıvıuade enzimática da incubação de diferentes preparaçoes de Lecitase imobilizada com polímero iônicos com. A quantidade de polímero foi de $50 \mathrm{mg} / \mathrm{g}$ de biocatalisador, e a incubação foi realizada a pH 7 (PEI de $25 \mathrm{kDa}$ ) ou de $\mathrm{pH} 5$ (DS de $20 \mathrm{kDa}$ ) e $25^{\circ} \mathrm{C}$. Outras condições são descritas na seção métodos. Incubação com DS é mostrado no painel A, a incubação com PEI é mostrado no painel B. Quadrados: CNBr Lecitase, Triângulos: Octil-Lecitase. Linha sólida: presença de polímero. A linha tracejada: ausência de polímero.

A incubação com PEI produziu um efeito completamente diferente. A atividade de ambas as preparações de enzimas imobilizadas aumentou nos primeiros minutos. Octil - Lecitase aumentou a atividade em $30 \% \%$, enquanto a $\mathrm{CNBr}$ - Lecitase o aumento da atividade foi mais do que duas vezes.

A enzima imobilizada covalentemente era mais sensível para o revestimento de polímero, tanto no efeito negativo de DS e no efeito positivo de PEI. Isto poderia ser explicado por várias razões. Primeiro, as regiões da proteína de exposição para a modificação pode ser diferente nas duas enzimas imobilizadas (o polímero é muito volumoso e não pode interagir com os domínios da proteína orientada para a superfície de suporte), e as possíveis alterações conformacionais provocadas pelos revestimentos podem ser diferentes. Em segundo lugar, a enzima imobilizada em agarose octil já tenha estabilizado a forma aberta, se os efeitos do polímero afetam a abertura/fechamento da enzima, este efeito pode ser perdido.

$\mathrm{O}$ efeito diferente dos dois polímeros pode estar relacionado com a diferença das áreas envolvidas dentro da modificação enzimática, há mais zonas catiônicas para DS e mais áreas aniônicos para os revestimentos com PEI, que aparentemente, tem um efeito completamente diferente da atividade da enzima.

\subsection{Efeito sobre o perfil de atividade /pH}

A Figura 2 mostra o perfil de 6 preparações de Lecitase sobre o perfil de atividade/pH. Octil- e $\mathrm{CNBr}$ Lecitase têm perfis muito diferentes; a preparação de octil tem a atividade máxima a $\mathrm{pH}$ mais elevado, o pH 10 (utilização de um pH mais elevado é difícil devido à hidrólise química de pNPB), 


\section{9 a 22 de outubro de 2014 \\ Florianópolis/SC}

enquanto que a preparação covalente tem a atividade máxima a um pH de 8. Usando CNBr Lecitase, as alterações do perfil de $\mathrm{pH} /$ atividade, derivada a partir do revestimento com o polímero são muito mais relevante.
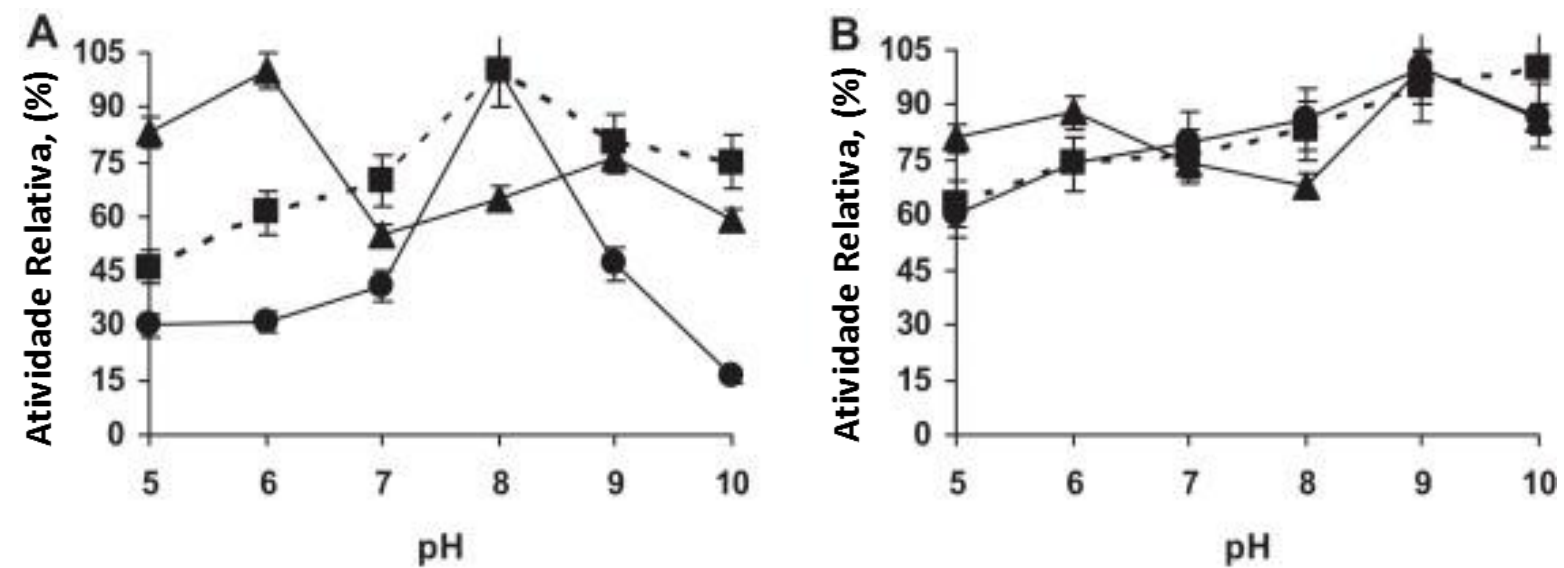

Figura 2. Efeito do pH sobre a atividade com pNPB de diferentes preparações de Lecitase. A atividade foi determinada como descrito na seção Métodos, a $25^{\circ} \mathrm{C} .100 \%$ foi a atividade máxima relativa para cada biocatalisador. Painel A: CNBr Lecitase, Painel B: octil-Lecitase. Quadrado, linha tracejada: preparação não modificada; Triângulos, linha sólida: PEI revestido biocatalisador; Círculos: biocatalisador DS revestido.

Para octil-Lecitase revestida com PEI, o $\mathrm{pH}$ ideal foi de 9. A atividade aumentou entre $\mathrm{pH}$ de 56, diminuindo depois disso até atingir um novo máximo de $\mathrm{pH} 9$. Estes dois valores máximos observados com ambas as preparações revestidas com PEI pode ser devido mudanças na intensidade da adsorção PEI sobre a enzima.

Usando o DS para o revestimento da enzima, a preparação com octil também possui a atividade máxima a pH 9 com uma queda na atividade a pH 10, enquanto que a preparação covalente tem o seu máximo com um pH 8, um máximo mais claro do que o uso de qualquer outra forma de preparação.

Assim, o tipo de polímero e a mudança de protocolo de imobilização a forma final da curva de Lecitase Ultra em atividade/pH, e o efeito é diferente utilizando ligação covalente ou a enzima adsorvida (no primeiro caso, as alterações são muito mais evidente).

\subsection{Estabilidade das diferentes preparações sob diferentes condições}

A Tabela 1 apresenta a meia-vida das 6 preparações de Lecitase imobilizada após inativação térmica a diferentes valores de $\mathrm{pH}$. O revestimento da enzima pode ter qualquer tipo de efeito sobre a estabilidade da enzima, principalmente na produção de alterações graves na atividade enzimática. Por exemplo, se a atividade aumenta pelo revestimento e este polímero move-se, devido às condições experimentais, o efeito hiperativante pode perder-se a temperatura drástica e produzir uma "aparente" inativação da enzima. 
Tabela 1 - Estabilidade térmica das diferentes preparações de Lecitase em diferentes condições. As meias-vidas são dadas em horas. Outras especificações estão descritos na seção métodos.

\begin{tabular}{llll}
\hline Biocatalyst & $\mathrm{pH} 5\left(50^{\circ} \mathrm{C}\right)$ & $\mathrm{pH} 7\left(55^{\circ} \mathrm{C}\right)$ & $\mathrm{pH} 9\left(53^{\circ} \mathrm{C}\right)$ \\
\hline Octyl & $1.5 \pm 0.1$ & $1 \pm 0.1$ & $0.70 \pm 0.05$ \\
Octyl-PEI & $9.1 \pm 0.5$ & $2.4 \pm 0.3$ & $0.75 \pm 0.05$ \\
Octyl-DS & $4.1 \pm 0.2$ & $0.6 \pm 0.05$ & $0.85 \pm 0.05$ \\
$\mathrm{CNBr}$ & $0.4 \pm 0.05$ & $0.5 \pm 0.05$ & $0.65 \pm 0.05$ \\
$\mathrm{CNBr}-\mathrm{PEI}$ & $2.7 \pm 0.1$ & $0.6 \pm 0.05$ & $0.55 \pm 0.05$ \\
$\mathrm{CNBr}-\mathrm{DS}$ & $1.4 \pm 0.1$ & $1.7 \pm 0.1$ & $1.80 \pm 0.1$ \\
\hline
\end{tabular}

A Tabela 1 mostra que, em geral, alguns efeitos de estabilização podem ser encontrados após o revestimento de enzimas, o que sugere que este efeito hiperativante não foi perdido por incubação sob tais condições. Mais uma vez, isto depende da preparação do derivado e do polímero utilizado. A pH 5, o revestimento de PEI aumentou significativamente a estabilidade de ambas as preparações de enzima (em cerca de 6 vezes ), enquanto o revestimento DS tem um efeito mais baixo (3-4 vezes). A $\mathrm{pH} 7$, o revestimento com PEI melhora por um fator de duas vezes a meia - vida da preparação em octil, enquanto que com DS melhorou 3 vezes a estabilidade da preparação covalente e reduzida pela metade a estabilidade da preparação de octil . A pH 9, apenas um aumento de 3 vezes na estabilidade da preparação covalente pode ser encontrado usando o revestimento com DS.
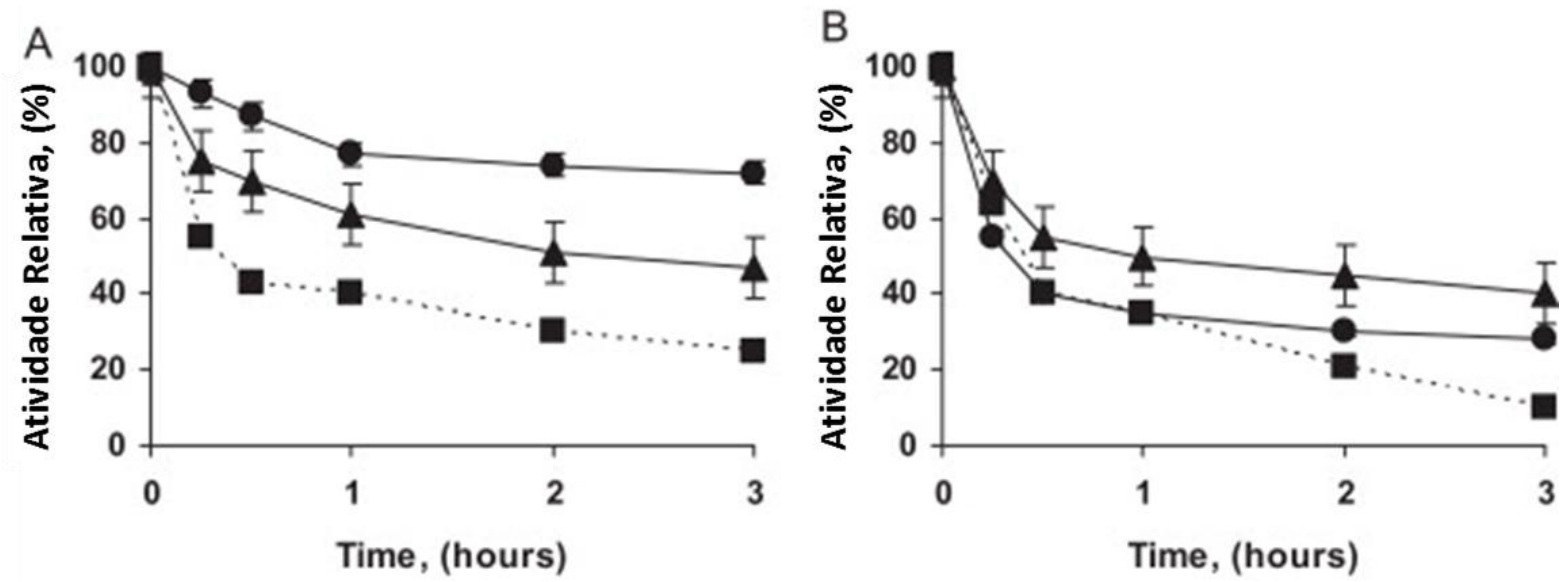

Figura 3 - Curso Inativação de diferentes preparações de Lecitase em 30\% acetonitrilo. A incubação

foi realizada como indicado na secção de Métodos. $100 \%$ foi a atividade inicial para cada biocatalisador. Painel A: CNBr Lecitase; Painel B: Octil-Lecitase. Quadrado, linha tracejada: preparação não modificada; Triângulos, linha sólida: PEI revestido biocatalisador; Círculos: biocatalisador DS revestido. 
A Figura 3 mostra a inativação dos 6 biocatalisadores em $30 \%$ de acetonitrilo (escolhido por ter uma taxa de inativação suficientemente rápida). CNBr Lecitase tinha uma estabilidade melhorada após incubação com ambos os polímeros, por 6-7 vezes usando PEI e por cerca de 30 vezes usando DS.

O efeito positivo do revestimento do polímero pode estar relacionado com uma hidrofilização da enzima com o nano-ambiente, que pode produzir alguma partição do solvente orgânico para longe da enzima como mostrado nos trabalhos de Wilson et al. (2004) e Fernandez-Lafuente et al. (1999).

Como a enzima pode ser exposta a uma concentração mais baixa de solvente, o que produz uma melhoria significativa na estabilidade da enzima. Por outro lado, este efeito foi mais baixa em octilLecitase provavelmente porque a enzima pode ser dessorvida a partir do suporte utilizando esta concentração de solvente (certa quantidade de proteína podia ser detectada no sobrenadante após inativação).

\section{CONCLUSÃO}

A incubação de Lecitase imobilizada em soluções de polímeros iônicos permite revestir as enzimas com o polímero, e este revestimento produziu alterações muito significativas nas propriedades da enzima. O revestimento com ambos DS e PEI produziu alguns efeitos benéficos sobre a estabilidade da enzima sob certas condições. Mais uma vez, este efeito positivo depende da preparação e das condições de inativação. Tendo em vista a melhoria da atividade em que o revestimento de PEI produziu em Lecitase, este efeito positivo do revestimento de polímero sobre a estabilidade da enzima sugere que o polímero pode permanecer adsorvido à enzima, mesmo a alta temperatura.

\section{AGRADECIMENTOS}

Os autores agradecem ao apoio do Governo Espanhol e ao CNPq (Brasil), pelas bolsas de doutorado para Ms. García-Galán (Governo Espanhol) e o Sr. dos Santos (CNPq, Brasil). Os autores gostariam de agradecer ao Sr. Ramiro Martínez (Novozymes, Espanha) por gentilmente fornecer as enzimas usadas na pesquisa.

\section{REFERENCIAS}

BARBOSA, O.; RUIZ, M.; ORTIZ, C.; FERNÁNDEZ, M.; TORRES, R.; FERNANDEZLAFUENTE, R.; Modulation of the properties of immobilized CALB by chemical modification with 2,3,4-trinitrobenzenesulfonate or ethylendiamine. Advantages of using adsorbed lipases on hydrophobic supports. Process. Biochem, v.47, p. 867-876, 2012.

BRADFORD, M.M. A rapid and sensitive method for the quantitation of microgram quantities of protein utilizing the principle of protein dye binding. Anal. Biochem, v.72, p. 248-254, 1976. 
DE MARIA, L.; VIND, J.; OXENBØLL, K.M.; SVENDSEN, A.; PATKAR, S;. Phospholipases and their industrial applications. Appl. Microbiol. Biotechnol. v.74, p.290-300, 2007.

FERNANDEZ-LAFUENTE， R.; ARMISÉN, P.; SABUQUILLO， P.; FERNÁNDEZLORENTE,G.; GUISÁN, J.M. Immobilization of lipases by selective adsorption on hydrophobic supports. Chem. Phys. Lipids. v.93, p.185-197, 1998.

FERNANDEZ-LAFUENTE,R. ; ROSELL，C.M. ; CAANAN-HADEN,L.; RODES， L. ; GUISAN, J.M. Facile synthesis of artificial enzyme nano-environments via solid-phase chemistry of immobilized derivatives: dramatic stabilization of penicillin acylase versus organic solvents. Enz. Microb. Technol., v.24, p. 96-103, 1999.

FERNÁNDEZ-LORENTE, G.; PALOMO,J.M.; CABRERA, Z.; GUISÁN, J.M.; FERNÁNDEZLAFUENTE, R. Specificity enhancement towards hydrophobic substrates by immobilization of lipases by interfacial activation on hydrophobic supports. Enz. Microb. Technol., v. 41, p. 565-569, 2007.

GARCIA-GALANA，C.; SANTOS，J.C.S.; BARBOSA，O.; TORRES， R.; PEREIRA， E. B.; CORBERAN, V. C.; GONÇALVES, L.R.B.; FERNANDEZ-LAFUENTE, R. Tuning of Lecitase features via solid-phase chemical modification: Effect of the immobilization protocol. Process. Biochem., v.49, p. 604-616, 2014.

SANTOS, J.C.S,; GARCIA-GALAN， C.; RODRIGUES， R.C.; SANTA'ANA， H.B.; GONÇALVES, L.R.B.; FERNANDEZ-LAFUENTE, R. Improving the catalytic properties of immobilized Lecitase via physical coating with ionic polymers. Enz. .Microb. Techn. v.60, p.1-8, 2014.

WILSON, L.; ILLANES, A.; ABIAN, O. ; PESSELA, B.C.C.; FERNANDEZ-LAFUENTE, R.; GUISAN, J.M.. Co-aggregation of penicillin $\mathrm{G}$ acylase and polyionic polymers: an easy methodology to prepare enzyme biocatalysts stable in organic media. Biomacrom., v.5, p.852-857, 2004. 